\title{
Application of PBL method in the Practice Teaching of General Surgery
}

\author{
Shu Jing ${ }^{\mathrm{a}}$, He Li ${ }^{\mathrm{b}}$ and Weihai Jiang ${ }^{\mathrm{C} *}$ \\ Beihua University, Jilin, Jilin,132013, China

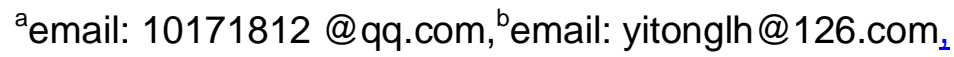 \\ 'email: 455066235@qq.com, "Corresponding author
}

Keywords: PBL (Problem-based learning); General surgery; Practice teaching;; Quality of teaching Abstract: General surgery is the basis of surgery and different from internal medicine due to its most important features, such as more skills and operation required for it. The practice of general surgery is crucial for medical students. The application of problem-based learning (PBL) is one of the important teaching methods for the clinical practice teaching in general surgery. In this study, five-year clinical medical students who were practicing in department of general surgery in our hospital were randomly divided into a PBL teaching group and a traditional teaching group, and the students' learning motivation, teaching satisfaction with PBL method, self-evaluation and knowledge acquisition were investigated. The results showed that the students' learning motivation, teaching satisfaction for the teaching, self-evaluation and knowledge acquisition in the PBL teaching group were significantly higher than those in the traditional education group, indicating that the teaching effect with PBL teaching method should be good and PBL method should be feasible.

Medical students have accepted the education in the basic medical theory and clinical knowledge before their clinical practice, but they are lack of the perceptual knowledge to the clinical knowledge and the ability to solve clinical and practical problem, as well as medical clinical skills. Although the period of clinical practice is not so long, it plays an important role in training medical students to become future qualified doctors as a link between the basics medicine and the clinical medicine, an important part of medical students learning career, and a clinical practice stage of the transition from the medical theory to the clinical practice and combining the theory with the clinical practice. General surgery is the basis of surgery and it is different from internal medicine due to one of its most important features, that is, more skills and operation required in surgery, especially in general surgery, so that you can often find many shortcomings of intern doctors worked at department of general surgery during the clinical teaching. This requires that teachers (physicians) responsible for the clinical teaching should guide them to correctly grasp and understand the practice in department of general surgery by paying more attention to the teaching "direction" and "key points" for helping the students successfully complete their learning task in the clinical practice.

In 1969, Howard Barrows, a neurology professor from the United States, created the problem-based learning (PBL) method at McMaster University in Canada, namely a learning model in which students lean something centered on problems or based on problems ${ }^{[1-2]}$. PBL has been applied in various fields of many colleges and universities, and attached importance to widely in the medical educational world.

During the long-term clinical teaching process of students' practice, we have made some attempts in the teaching of general surgery with PBL method based on the teaching reform and practice in our hospital, and achieved initial results. In this study, our thinking and practice in the application of PBL in the clinical practice teaching of general surgery are investigated. 
Objects and Methods. Sixty clinical medical intern form five-year undergraduates enrolled by Beihua University were randomly selected and divided into PBL teaching group and traditional teaching group, 30 students in each group.

Methods for students in the traditional teaching group. Students in the traditional teaching group completed their clinical practice in general surgery mainly by the teachers' instructions, that is, guiding the students to learn to make the rounds of the wards and conduct the physical examination, asking the students to raise questions and answering the questions by the teachers, and explaining the key points by the teachers.

Methods for students in the PBL method group. (1) Selecting tasks: The teachers carefully prepared the case data and related pictures, elaborately conceived a series of "problems" related to the clinical practice. The designed problems should be progressively difficult, in which more attention should be paid to the relation and logical relationship among the knowledge points, the basic knowledge and clinical knowledge, and the infiltration of them each other. Here, several cases were taken as examples. Case one (colon cancer): "Whether the diagnostic basis of the patient's colon cancer is sufficient or not?"; "What are the specific requirements for the preoperative bowel preparation?"; "What are the matters needing attention for the monitoring and treatment after surgery?"; "Whether a chemical treatment is needed after operation?". Case two (breast cancer): How to divide the clinical stages of the patient' breast cancer?"; "Is breast-conserving surgery or modified radical mastectomy suitable for the treatment of breast cancer?"; "Whether the radiotherapy, chemotherapy or endocrine therapy is required or not after operation?". Case three (severe acute pancreatitis): "Whether the diagnostic basis for the patient's severe acute pancreatitis is sufficient or not?"; "What are the relations between the pathophysiological changes and the clinical treatment?"; "How to determine the timing of surgery?"; "What are the main points during the operation and after the operation?"; "What is the significance of somatostatin in the treatment of severe acute pancreatitis?". Case four (obstructive jaundice): "What are the causes of the patient's obstructive jaundice?"; "What are the pathological changes in liver and biliary tract?"; "How to select a correct surgical procedure for the patient?"; "What are the matters needing attention during the perioperative period?". Case five (thyroid tumor): "What are the main points of clinical treatment and operation indications of the patient's thyroid tumor?". (2) Students' preparation: Aiming at the above-mentioned problems, some related reference books were recommended to the students and they were also encouraged to collect relevant information through internet. The students were asked to write speech outlines and raise some new questions based on cases described above, including the pathogenesis, pathological and pathophysiological changes, clinical manifestations, physical examination, laboratory examination, diagnosis, treatment (nonsurgical treatment and surgical treatment) and prognosis of the cases, and then they were asked to give their presentation and organized to discuss all the issues in groups. (3) Class discussion: Taking a voluntary grouping principle, the students could freely choose their classmates to organize a discussion group, 4 6 students in each group to give their presentation one by one and discuss the cases on their point of view. During the class discussion, the students were encouraged to debate and record problems to be solved, the teachers should listen to them carefully or record problems unclear or needed to be corrected, and finally the heads of groups were asked to sum up the discussion simply. (4) Teachers' explanation: Aiming at the problems found in the students' discussion, the teachers should comment on the students' performance, explain the key points, and answer the students' questions and point out the knowledge points that the students should focus on. (5) Clinical application: Aiming at the related problems and according to the patient data, the answers to the questions were verified and modified to stimulate the students' learning interest and 
consolidate their memory.

Unified assessment. (1) Questionnaire survey: The questionnaire was focused on the students' learning motivation, self-evaluation, teaching satisfaction, interest in the practice of general surgery and the way to acquire the knowledge. (2) Theoretical examination: A unified theoretical examination paper was used for the assessment of general surgery theory. The difference between the two groups was compared and the data were analyzed with statistical software SPSS13.0.

Results. The results showed that the learning motivation, self-evaluation, the interest in the practice of general surgery in students in the PBL teaching group were significantly higher than those in the traditional teaching group; $98 \%$ of the students in the PBL teaching group were satisfied with the PBL method; approaches to acquire the knowledge in the PBL teaching group were from 6 to 10, while those in the traditional teaching group were only from 2 to 4; the average scores of theory examination of students in the PBL teaching group were $85.5 \pm 5.3$ ), while those in the traditional teaching group were $76.5 \pm 5.6)$, showing a statistically significant difference $(\mathrm{P}<0.05)$.

Discussion. General surgery is the basis of all different clinical surgical subjects, plays an important role in the clinical practice of medical students, and an important bridge for medical students growing into clinicians. One of medical students' dreams is to become a surgeon in a department of general surgery and most of them like entering an Affiliated Hospital of a medical school for their clinical practice. It is well known that medical students learn the basic theoretical knowledge of medicine in the stage of theoretical study and the knowledge is validated and understood further during the clinical practice. Clinical medicine is a practical science and empirical science and not merely a theoretical science. The combination of practice, thinking and knowledge is the direction of clinical medical practice ${ }^{[3-11]}$.

Through the practice of clinical teaching for many years, we gradually realized insufficiencies of the traditional teaching mode, in which the students were passive in learning and the teaching effect was not so good. Since the application of PBL teaching method in the clinical practice of general surgery, the students could have access to a large amount of information, and organize, digest and absorb the knowledge due to the sufficient pre-class preparation, greatly improving their independent learning ability. Through the group discussion, the answers to the questions can be found and some new problems can be put forward, the students' critical thinking may be developed, their analytical and problem-solving skills may be trained, a good relationship between students and teachers can be established, and their communication skills and cooperation sense can be cultivated, reflecting a good interaction between teaching and learning, to realize the goal required for teaching to cultivate students' comprehensive ability ${ }^{[3]}$.

The application of PBL teaching method can make the transformation from the exam-oriented education mode to a quality education mode, may help to improve the overall quality of students, can provide more space for learning and more learning autonomy for students. However, to fundamentally change the traditional education mode that has been accustomed to by students over the years, a step-by-step adaptation process is required, and the scientific evaluation system corresponding to it should be established. In addition to the final examination, how to quantify students' performance during the teaching process with PBL method also need to grope in practice and determine a complete set of flexible assessment methods, in order to adapt to the reform of the teaching method ${ }^{[12]}$.

\section{References}

[1] Rhem J.Problem-based learning:an introduction [J]. The National Teaching \& Learning Forum, 1998,8(1):1. 
[2] Wang Tianbao, Deng Meihai, Lun Lixian, et al. Application of PBL in the practical clinical teaching of general surgery [J].China Medical Innovation, 2007, 2(14): 60-61.

[3] Wu Jieping. Experience of growing [J]. Journal of Capital Medical University, 2006, 27(1): 768-771.

[4] Yang Yiqun, Lu Yingqing, Zeng Yong. PBL and instruction of self-designing experiments in medical functional disciplines [J]. China Higher Medical Education, 2006, 12(1): 63-65.

[5] Yang Dinghua. Current situation and reflection on medical education [J]. Journal of Guangxi Medical University [J], 2004, 9(21): 52-54.

[6] Liu Zhonghai. Experiment, scientific innovation and quality education [J]. Research and Exploration in Laboratory [J], 2002, 21(5): 7-9.

[7] Burgess A, McGregor D, Mellis C. Applying guidelines in a systematic review of team-based learning in medical schools [J]. Acad Med, 2014,89:4-12.

[8] Parmelee D, Michaelsen LK, Cook S, Hudes PD. Team-based learning: A practical guide: AMEE guide [J]. Med Teach. 2012,34:e275-e287.

[9] Burgess AW, Ramsey-Stewart G, May J, Mellis C. Team-based learning methods in teaching topographical anatomy by dissection. ANZ J Surg [J]. 2012,82:457-460.

[10] Thompson BM, Levine RE, Kennedy F, Naik AD, Foldes CA, Coverdale JH, et al. Evaluating the quality of learning-team processes in medical education: development and validation of a new measure [J]. Acad Med.2009,84:10.

[11] Wiener H, Plass H, Marz R. Team-based learning in intensive course format for first-year medical students [J].Croat Med J. 2009,50:69-76.

[12]Jie H. Research on the PBL in the practical clinical teaching of general surgery [J]. Contemporary Medicine.2010, 16(192):164-165. 